\title{
A competitividade das exportações de milho do Brasil para a União Europeia no período de 2000 a 2014
}

\section{The Competitiveness of Corn Exports of Brazil for the European Union in the Period 2000-2014}

\author{
Sílvia Letícia Bampi \\ Economista. Mestranda do Programa de Pós-Graduação em Economia da \\ Universidade do Vale do Rio dos Sinos - Unisinos, Rio Grande do Sul, Brasil \\ http://orcid.org/0000-0003-2340-8386 \\ lety_silvia@hotmail.com

\section{Cristiano Villanova de Paula} \\ Administrador. Mestrando do Programa de Pós-Graduação em Economia da \\ Universidade do Vale do Rio dos Sinos - Unisinos, Rio Grande do Sul, Brasil \\ http://orcid.org/0000-0002-0489-8810 \\ villanovacristiano@gmail.com \\ Julcemar Bruno Zilli \\ Economista, Doutor em Economia Aplicada (ESALQ/USP) e Professor/Pesquisador \\ da Faculdade de Ciências Econômicas, Administrativas e Contábeis da Universidade \\ de Passo Fundo (FEAC/UPF) \\ http://orcid.org/0000-0001-6649-3440 \\ jbzilli@upf.br \\ Fecha de recepción: 16 de mayo de 2016 \\ Fecha de aceptación: 07 de julio de 2016
}

Sugerencia de citación: Bampi, S. L., Villanova de Paula, C. \& Zilli, J. B. (2016). A competitividade das exportações de milho do Brasil para a União Europeia no período de 2000 a 2014.

tiempo\&economía, 3(2), 115-136, doi: http://dx.doi.org/10.21789/24222704.1130 


\section{Resumo}

O presente estudo objetiva verificar a competitividade das exportações brasileiras de milho, buscando indícios de criação e/ou desvio de comércio com à União Europeia. Para tanto, será caracterizado o cenário do mercado mundial do grão, descrevendo-se o perfil de comércio entre UE e Brasil e apresentando os principais estudos empíricos relacionados. A mensuração dos Índices de Vantagens Comparativas Reveladas (IVCR) e do Índice de Orientação Regional (IOR) auxiliará na identificação das vantagens comparativas do milho brasileiro. Os principais resultados do IOR elencam que as exportações de milho do Brasil não estão orientadas para a UE com exceção dos anos de 2003, 2004, 2006, 2007 e 2008. Da mesma forma, o IVCR identificou que o país não apresenta vantagem comparativa revelada na produção de milho em relação ao período analisado. A ampliação e integração dos mercados agrícolas pode ser capaz de impulsionar os fluxos comerciais entre os países envolvidos, permitindo crescimento e desenvolvimento das economias, através do livre comércio.

Palavras-chave: Comércio Internacional, Competitividade, Orientação, Milho

Códigos JEL: F1, Q17

\section{Abstract}

The present study aimed to verify the competitiveness of Brazilian corn exports, seeking evidence of creation and/or diversion of trade with the European Union. To this, was characterized the scene of the world grain market, was described the trade profile between the EU and Brazil and presented the main related empirical studies. The measurement of Comparative Advantage Revealed Index (IVCR) and the Regional Orientation Index (IOR) assist in identifying the comparative advantages of Brazilian corn. The main results of the IOR said that corn exports from Brazil are not oriented towards the EU with the exception of the years 2003, 2004, 2006, 2007 and 2008. Similarly, the IVCR identified that the country does not have comparative advantage revealed in corn production over the period. The expansion and integration of agricultural markets may be able to boost trade flows between the countries, allowing growth and development of the economies through free trade.

Keywords: International Trade, Competitiveness, Orientation, Corn

JEL Codes: F1, Q17 


\section{Introdução}

A globalização e os efeitos da integração regional modificaram o cenário do comércio internacional. Gorender (1995) reflete que durante três décadas após a Segunda Guerra Mundial, a economia como um todo desenvolveu-se a taxas historicamente altas. Na Europa Ocidental e nos Estados Unidos, por exemplo, as empresas passaram a praticar o jogo de soma positiva, incrementando seus lucros e sua acumulação do capital, melhorando, por conseguinte, o bem-estar social. $\mathrm{O}$ impulso desenvolvimentista atingiu diversos países do até então conhecido Terceiro Mundo a contar pelo Brasil.

A concorrência entre as nações industrializados acabou por conduzir à formação de blocos econômicos regionais. Destes Gorender (1995) destaca como sendo os três principais: o Tratado de Livre Comércio da América do Norte (NAFTA), a União Europeia (UE) e o bloco informal do Extremo Oriente. No âmbito brasileiro surgiria em 1994 o Mercado Comum do Sul (MERCOSUL). No entanto, como menciona Gorender (1995), a política de blocos, apesar de intensificar o intercâmbio entre os membros do bloco e com parceiros externos, permitiu a prática protecionista, gerando indícios de surgimento de desvio de comércio.

O pioneirismo da utilização dos conceitos de desvio e criação do comércio é atribuído a Viner (1950). Baumann, Canuto e Gonçalves (2004) mencionam que criação de comércio ocorre se os países puderem importar do bloco produtos a um custo menor do que na situação anterior a existência de um acordo. Caso contrário, prevalecerá o fenômeno de desvio de comércio. Neste contexto, Reis e Azevedo (2008) explicam que ocorre criação de comércio quando se verificar o aumento do comércio intrabloco com origem em produtos onde os países membros são mais eficientes na produção em relação ao resto do mundo, sendo competitivos não apenas no mercado regional, mas também nos mercados internacionais.

No âmbito da globalização e da integração comercial a segurança alimentar é um tema que faz parte do cotidiano. Segundo dados da Organização das Nações Unidas para Alimentação e Agricultura (FAO, 2015), cerca de 850 milhões de pessoas passam fome no mundo. A alta dos preços alimentícios, em conjunto com o contexto da insegurança alimentar, tem provocado diversos debates que influenciam o cenário do comércio internacional. A agricultura é o setor mais crítico nas negociações na esfera do multilateralismo, influenciando diretamente mercados como o de grãos.

O mercado do milho, a exemplo disto, é liderado por países da América do Norte (NAM), China, Brasil e UE 15 que produzem, conjuntamente, cerca de 463,5 milhões de toneladas de milho, com uma participação de $74,7 \%$ do total produzido no mundo. A União Europeia também importa quantidades significativas de milho, porém com uma participação no comércio mundial ainda reduzida. Os principais países importadores de milho são pertencentes à região chamada de "resto do mundo", Oriente Médio, ASEAN e CAN. Considerando apenas os países do Mercosul, observa-se que há um excedente de 10,6 milhões de toneladas de milho que são exportados para outros países. (Alvim \& Waquil, 2005).

O milho também é considerado um produto estratégico para a segurança alimentar mundial. O cereal é utilizado para a nutrição humana e alimentação animal, principalmente na avicultura, suinocultura e bovinocultura (produção de rações). Além dessas finalidades, 
o milho é cultivado para a extração do bioetanol, principalmente nos Estados Unidos, fato que justifica o aumento da sua produção neste país. Dessa forma, o aumento do consumo mundial de milho, em suas diversas formas, contribui para que o mesmo obtenha importância no contexto da produção em esfera global. Favro, Cardarelli e Camara (2015) enfatizam que as exportações de milho pelo Brasil passaram a adquirir certa importância principalmente na última década - especificamente após 2004. Nas últimas safras tem sido observada uma tendência geral de crescimento nas exportações de milho em virtude das condições externas favoráveis.

Com a internacionalização dos mercados, como mencionam Brandão et al. (2012), e expansão do agronegócio e da agricultura brasileira, as exportações têm ocupado um lugar de destaque como fator fundamental para o crescimento econômico do país, dadas essas acepções, a orientação para o mercado externo, tem sido evocada em diversos estudos. Objetivando potenciais clientes, como frisa Slater (2001), o estudo da orientação permite uma avaliação ex-ante de informações de mercado, sendo uma fonte distinta de vantagem competitiva.

Deste modo, diversas são as metodologias empregadas para verificar a orientação destes mercados, como também sua competitividade e os desvios e criações de comércio. Yeats (1997) apresenta a análise conjunta do Índice de Orientação Regional (IOR) que indica em quais produtos o comércio intrabloco cresceu e do Índice de Vantagem Comparativa Revelada (IVCR) que demonstra se nesses produtos os países membros do bloco possuem uma vantagem comparativa revelada em relação ao resto do mundo. Reis e Azevedo (2008) demonstram que a outra metodologia usada é o modelo gravitacional que tem sido utilizado com sucesso para explicar o comércio "normal" entre dois países ou regiões que não façam parte de um Acordo Preferencial de Comércio.

Usualmente as estimativas de criação e desvio de comércio são calculadas por meio de modelos de equilíbrio parcial, como estabelece Guimarães (2000), em que são desconsiderados os efeitos secundários da liberalização comercial através da utilização de insumos importados mais baratos na produção dos bens domésticos. As equações do modelo de equilíbrio parcial de Laird e Yeats (1986) ${ }^{1}$ permitem calcular a criação e o desvio de comércio que ocorreriam a partir de uma redução tarifária preferencial. Além disso, a avaliação dos acordos comerciais deve incorporar os efeitos dinâmicos associados a economias de escala, fluxos de investimentos, incorporação tecnológica e ganhos decorrentes dos processos de aprendizagem, por exemplo, que em grande parte não são captados pelas análises estáticas contidas naquelas estimativas. Nonnenberg e Mendonça (1999) destacam, ainda, a utilização de modelos de equilíbrio geral que capturem as modificações no comércio e em outras variáveis econômicas decorrentes, entre outros fatores, da política comercial.

Nesse sentido, o objetivo do presente estudo é verificar a competitividade e a orientação das exportações brasileira de milho frente à União Europeia. O estudo é subdividido em três seções: a primeira caracteriza o panorama atual do mercado mundial de milho, a segunda descreve o perfil de comércio entre UE e Brasil e a terceira apresenta os principais estudos empíricos relacionados.

1 The Unctad trade policy model: a note on methodology, data and uses. Genebra, 1986. 


\section{Mercado Mundial e Brasileiro de Milho}

O milho é hoje o cereal mais produzido no mundo. Para a safra de 2015/2016 é esperada uma produção de aproximadamente 970 milhões de toneladas, segundo dados do Departamento de Agricultura dos Estados Unidos (USDA, 2016). Deste volume, também de acordo com o USDA (2016), pode-se verificar que a produção mundial se concentra, basicamente, em três grandes países produtores: Estados Unidos, China e Brasil, respectivamente, representando $67,4 \%$ da produção mundial de milho. Nota-se que a partir da safra de $2000 / 2001$, segundo USDA (2016), a produção mundial de milho passa a se intensificar, atingindo uma produção 70\% maior em 2014/2015, conforme retratado na Figura 1. Nesta, é possível analisar que ao longo dos anos o consumo manteve-se crescente, reforçando a importância do cereal e dos ganhos de produtividade aplicados na produção.

Figura 1. Evolução da Produção Mundial de Milho de 2000 a 2015

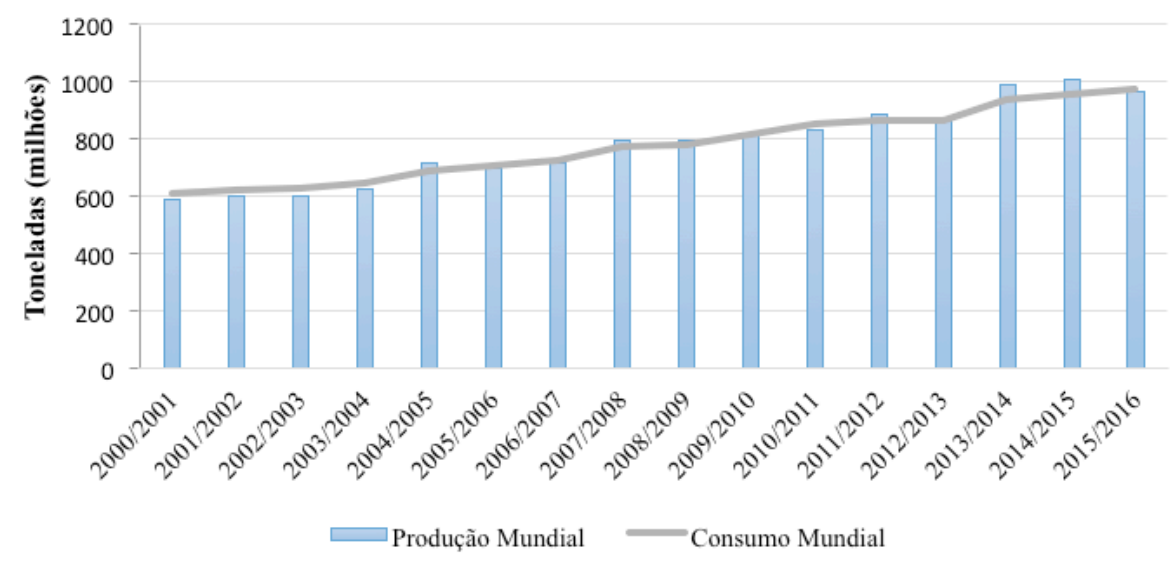

Fonte: USDA (2016).

O Brasil se encontra na terceira posição no ranking de produtores e, para a safra 2015/2016, são aguardados 84 milhões de toneladas, principalmente, devido aos aumentos de produtividade, bem como a valorização da produção na segunda safra (safrinha). De acordo com a Embrapa Milho e Sorgo (2012) a produção brasileira de milho tem dois destinos: o consumo no estabelecimento rural, destinando-se ao consumo animal em sua maior parte e também ao consumo humano e, segundo, à oferta do produto no mercado consumidor, onde se tem fluxos de comercialização direcionados para fábricas de rações, indústrias químicas, mercado de consumo in natura e exportações. Nas safras consideradas na Tabela 1 o país representou em média $8,6 \%$ da produção mundial. 
Tabela 1. Principais Produtores Mundiais de Milho no Período 2012/2013 a 2015/2016

\begin{tabular}{ccccc}
\hline \multicolumn{5}{c}{$\%$ do Total } \\
\hline Países & $\mathbf{2 0 1 2 / 2 0 1 3}$ & $\mathbf{2 0 1 3 / 2 0 1 4}$ & $\mathbf{2 0 1 4 / 2 0 1 5}$ & $\mathbf{2 0 1 5 / 2 0 1 6}$ \\
\hline Estados Unidos & $31,4 \%$ & $35,4 \%$ & $35,8 \%$ & $35,6 \%$ \\
China & $23,6 \%$ & $22,0 \%$ & $21,4 \%$ & $23,2 \%$ \\
Brasil & $9,4 \%$ & $8,1 \%$ & $8,4 \%$ & $8,7 \%$ \\
União Europeia & $6,8 \%$ & $6,5 \%$ & $7,5 \%$ & $6,0 \%$ \\
Argentina & $3,1 \%$ & $2,6 \%$ & $2,7 \%$ & $2,8 \%$ \\
Ucrânia & $2,4 \%$ & $3,1 \%$ & $2,8 \%$ & $2,4 \%$ \\
México & $2,5 \%$ & $2,3 \%$ & $2,5 \%$ & $2,4 \%$ \\
Índia & $2,6 \%$ & $2,4 \%$ & $1,3 \%$ & $2,2 \%$ \\
Canadá & $1,5 \%$ & $1,4 \%$ & $1,1 \%$ & $0,7 \%$ \\
África do Sul & $1,4 \%$ & $1,5 \%$ & $14,3 \%$ & $14,7 \%$ \\
Outros & $15,3 \%$ & $14,5 \%$ & $100,0 \%$ & $\mathbf{1 0 0 , 0 \%}$ \\
\hline Total & $100,0 \%$ & $100,0 \%$ &
\end{tabular}

Fonte: USDA (2016).

Logo após o Brasil (vide Tabela 1), se encontra a União Europeia que representou em média nas safras de 2012/2013 a 2015/2016 de cerca de 6,7\% da produção mundial do grão, seguida pela Argentina (2,8\%), Ucrânia (2,7\%), México $(2,4 \%)$, Índia (2,4\%), Canadá $(1,4 \%)$ e África do Sul $(1,2 \%)$. Nas Projeções do Ministério da Agricultura, Pecuária e Abastecimento (2015) entre 2019/2020, a produção deverá ficar em 70,12 milhões de toneladas e o consumo em 56,20 miIhões de toneladas. Esses resultados indicam que o Brasil deverá fazer ajustes no seu quadro de suprimentos para garantir o abastecimento do mercado interno e obter excedente para exportação.

Analisando a Tabela 2, observa-se que o consumo mundial de milho apresenta crescimento em um período recente. Os números do USDA (2016) salientam que os principais consumidores de milho no mundo são os Estados Unidos e a China, representando, em média, 52\% deste total nos 4 anos apresentados na Tabela. A União Europeia, no entanto, ocupa a terceira posição representando uma média de $8 \%$. Apesar de se destacar como o principal consumidor mundial de milho, os Estados Unidos vêm apresentando um declínio em seu consumo, e este volume tem se tornado mais pulverizado, com nenhum outro país absorvendo de forma ampla esta quantidade.

As exportações do milho tiveram um aumento considerável nas últimas safras (vide Tabela 3), mantendo o nível nas últimas duas safras analisadas. Atualmente, o mercado de exportação de milho, como destaca o USDA (2016), é praticamente dominado por quatro países: Estados Unidos da América, Brasil, Ucrânia e Argentina. Juntos, esses países representaram, aproximadamente, 85\% das exportações mundiais na safra 2015/2016. Entre estes players, Estados Unidos e Brasil se caracterizam por serem grandes produtores e também consumirem boa parte da sua produção. Já a Ucrânia e a Argentina destinam mais de $66 \%$ e $62 \%$ da sua produção, respectivamente, para o mercado externo, demonstrando assim grande dependência das exportações para escoarem seu milho. 
Tabela 2. Principais Consumidores Mundiais de Milho no Período 2012/2013 a 2015/2016

\begin{tabular}{ccccc}
\hline \multicolumn{5}{c}{ \% do Total } \\
\hline Países & $2012 / 2013$ & $\mathbf{2 0 1 3 / 2 0 1 4}$ & $\mathbf{2 0 1 4 / 2 0 1 5}$ & $\mathbf{2 0 1 5 / 2 0 1 6}$ \\
\hline Estados Unidos & $30,3 \%$ & $31,1 \%$ & $31,4 \%$ & $30,9 \%$ \\
China & $23,0 \%$ & $22,1 \%$ & $21,0 \%$ & $22,1 \%$ \\
União Europeia & $8,0 \%$ & $8,1 \%$ & $8,1 \%$ & $7,8 \%$ \\
Brasil & $6,0 \%$ & $5,8 \%$ & $5,9 \%$ & $5,9 \%$ \\
México & $3,1 \%$ & $3,4 \%$ & $3,6 \%$ & $3,6 \%$ \\
Índia & $2,0 \%$ & $2,1 \%$ & $2,3 \%$ & $2,2 \%$ \\
Japão & $1,7 \%$ & $1,6 \%$ & $1,5 \%$ & $1,5 \%$ \\
Egito & $1,4 \%$ & $1,4 \%$ & $1,4 \%$ & $1,5 \%$ \\
Canadá & $1,3 \%$ & $1,3 \%$ & $1,3 \%$ & $1,4 \%$ \\
Indonésia & $1,3 \%$ & $1,3 \%$ & $1,3 \%$ & $1,3 \%$ \\
África do Sul & $1,3 \%$ & $1,2 \%$ & $1,2 \%$ & $1,1 \%$ \\
Coréia do Sul & $1,0 \%$ & $1,0 \%$ & $1,1 \%$ & $1,0 \%$ \\
Outros & $19,7 \%$ & $19,5 \%$ & $19,8 \%$ & $19,6 \%$ \\
\hline Total & $79,3 \%$ & $79,4 \%$ & $79,1 \%$ & $79,3 \%$ \\
\hline
\end{tabular}

Fonte: USDA (2016).

Analisando um período maior, entende-se que o movimento das exportações mundiais mudou significativamente, se comparados aos das safras de dez anos atrás (USDA, 2016). Este cenário se explica devido as mudanças ocorridas no mercado do grão nos últimos anos, onde a China, que se posicionava como uma exportadora de milho na safra 2005/2006, passa a se caracteriza como importadora. É valido destacar que, Brasil e Ucrânia ascenderam a escala de produção e exportação, sendo que, na safra 2015/2016 foram responsáveis por aproximadamente $38 \%$ do total exportado.

Tabela 3. Exportações Mundiais de Milho por países no período 2012/2013 a 2015/2016*

\begin{tabular}{ccccc}
\hline Países & $\mathbf{2 0 1 2 / 2 0 1 3}$ & $\mathbf{2 0 1 3 / 2 0 1 4}$ & $\mathbf{2 0 1 4 / 2 0 1 5}$ & $\mathbf{2 0 1 5 / 2 0 1 6}$ \\
\hline Estados Unidos & 18,55 & 48,78 & 47,36 & 41,91 \\
Brasil & 24,95 & 20,97 & 33,00 & 28,00 \\
Ucrânia & 12,73 & 20,00 & 19,66 & 15,50 \\
Argentina & 18,69 & 17,10 & 18,50 & 17,00 \\
Paraguai & 2,83 & 2,37 & 3,29 & 2,30 \\
Índia & 4,69 & 3,87 & 1,11 & 0,70 \\
Outros & 12,70 & 18,01 & 16,77 & 13,99 \\
\hline Total & 95,12 & 131,10 & 139,69 & 119,40 \\
\hline
\end{tabular}

Fonte: USDA (2016).

* Milhões de Toneladas. 
Nas últimas três safras (2012/2013 a 2014/2015) as importações mundiais de milho avançaram 19\% (Tabela 4). Já para a safra 2015/2016 é esperado um total de 128 milhões de toneladas destinadas às importações de acordo com dados do USDA (2016). Nota-se, porém, neste contexto, que o cenário importador de milho mundial passa por uma alteração em seu quadro. Antes importadores, países tradicionais diminuíram o ritmo de seus volumes, dando espaço assim a países menores e um volume importado muito mais pulverizado. Dentre estes novos compradores destacam-se países como México, Egito, Coréia do Sul e Irã, demonstrando assim um mercado consumidor cada vez mais diversificado para o milho.

Tabela 4. Importações Mundiais de Milho por países no período 2012/2013 a 2015/2016*

\begin{tabular}{ccccc}
\hline Países & $\mathbf{2 0 1 2 / 2 0 1 3}$ & $\mathbf{2 0 1 3 / 2 0 1 4}$ & $\mathbf{2 0 1 4 / 2 0 1 5}$ & $\mathbf{2 0 1 5 / 2 0 1 6}$ \\
\hline Japão & 14,41 & 15,12 & 14,66 & 14,70 \\
México & 5,68 & 10,95 & 11,27 & 11,30 \\
União Europeia & 11,36 & 15,95 & 8,76 & 16,00 \\
Coréia do Sul & 8,17 & 10,41 & 10,17 & 10,00 \\
Egito & 5,06 & 8,73 & 7,83 & 8,00 \\
Irã & 3,70 & 5,50 & 6,20 & 5,00 \\
Outros & 51,39 & 57,29 & 64,27 & $\mathbf{6 3 , 3 0}$ \\
\hline Total & $\mathbf{9 9 , 7 7}$ & $\mathbf{1 2 3 , 9 5}$ & $\mathbf{1 2 3 , 1 4}$ & $\mathbf{1 2 8 , 3 0}$ \\
\hline
\end{tabular}

Fonte: USDA (2016).

* Milhões de Toneladas

Apesar de o Brasil não ter tradição de exportador e importador de milho em grãos, a exportação do grão passou a adquirir alguma importância nos últimos, dado o potencial para participar do mercado externo visível no país que se concretizou recentemente. Caldarelli e Bacchi (2012) destacam que o incremento da produção brasileira de milho se dá por uma posição mais competitiva do país em decorrência de fatores microeconômicos, como a maior rentabilidade, consequência do aumento do preço recebido pelo produtor, e de fatores macroeconômicos, como a eliminação de tarifas de produtos importados.

Favro, Caldarelli e Camara (2015) no âmbito interno, a maior inserção do milho brasileiro no comércio exterior tem como principal reflexo os efeitos sobre a competitividade de cadeias que apresentem forte dependência deste grão como insumo, a exemplo da produção de rações. O fator positivo, neste cenário seria a maior coordenação e organização da cadeia, decorrentes das maiores exportações e necessidade de um mercado mais organizado. Irwin e Good (2009) mencionam que externamente, o Brasil desponta como um grande player no mercado internacional do referido grão, podendo ocupar a posição de grande ofertante mundial. Assim, após apresentado o panorama mundial do mercado de milho e a posição ocupada pelo Brasil neste contexto, o estudo elenca na próxima seção o perfil das relações de comércio entre o país e o bloco europeu. 


\section{Perfil das Relações Comerciais da UE com o Brasil}

A UE representa o estágio mais avançado do processo de formação de blocos econômicos no contexto da globalização. O PIB da UE em 2014 representou 13.9trilhões de euros, de acordo com dados da EUROSTAT (2015). Na atual fase vivida pela UE no seu processo de integração está marcado por resultados negativos e pela resistência e insatisfação do cidadão europeu, colocando o modelo de integração europeu em questionamento. Um problema latente na UE é definir claramente qual é sua identidade, no sentido do que esta união é, para que serve e o que ela representa hoje, visto que as suas características se modificaram ao longo dos anos e o bloco não tem o mesmo papel que exercia quando da sua criação.

A respeito do nível de comércio do bloco Gorender (1995) comenta:

A UE dinamizou notavelmente o intercâmbio econômico dentro do seu âmbito, alçandose a condições de concorrência com os Estados Unidos e o Japão. Seu discurso oficial em favor da liberalização não impede práticas protecionistas em setores específicos e diante de casos concretos. Assim é que aplicou medidas de proteção de sua agricultura diante das exportações agrícolas dos Estados Unidos e obrigou o Japão a adotar cotas voluntárias nas suas exportações de automóveis e de equipamentos microeletrônicos. (p. 101)

Desde a sua formação, até o momento verifica-se me forte intercâmbio comercial intra-bloco, o que por sua vez, justifica a formação do mesmo. Alguns países como Malta, Reino Unido e Grécia apresentam um nível de exportação extra-bloco que superam o intrabloco, enquanto os demais países exportam em proporções maiores para membros do bloco. A Figura 2 mostra para o ano de 2013 o comparativo entre as Exportações Intra-UE e as Extra-EU por estado membro. Segundo dados da Eurostat (2015) o comércio dentro da União Europeia cresceu em média 32\% de 2005 a 2014, esse crescimento foi puxado principalmente por países como o Luxemburgo, República Checa e a Eslováquia (cerca de 80 \% do comércio total intra-UE). O percentual do comércio total de mercadorias resultante dos fluxos intra-UE e extra-UE variou consideravelmente entre os Estados-Membros, o que reflete os laços históricos e a localização geográfica.

Figura 2. Exportações Intra-UE em comparação com as Extra-UE por estado membro para o ano de 2013 (\% de participação do total das exportações).

100

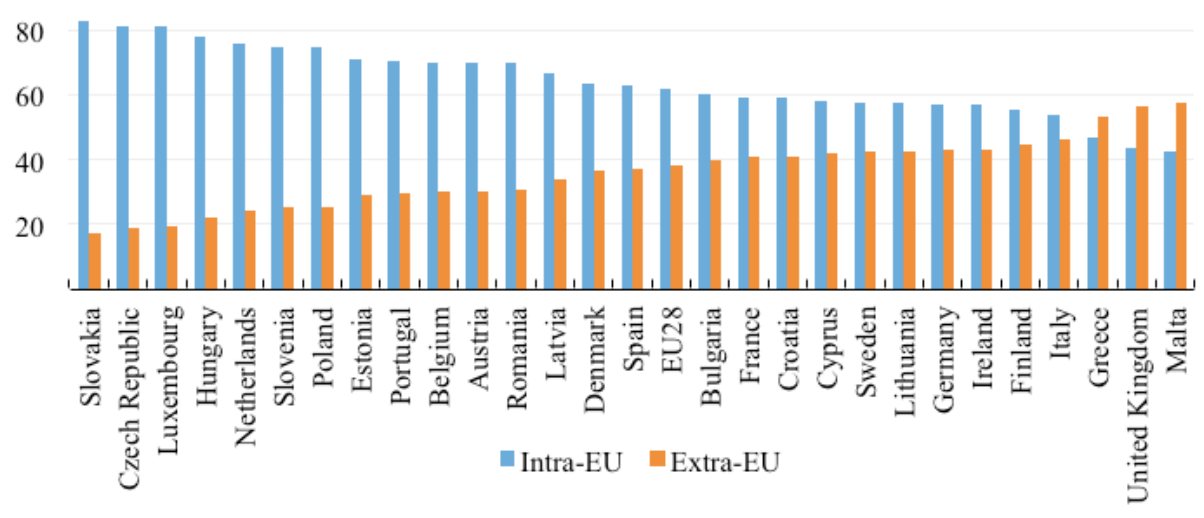

Fonte: Eurostat (2016).

tiempo\&economía

Vol. $3 \mathrm{~N}^{\circ} 2$ - II semestre de 2016 
As relações econômicas entre o Brasil e o próprio Mercosul com os países da Europa Ocidental sempre foram bastante estreitas, devido às proximidades históricas e culturais, conforme enfatiza Kume et al. (2004)

A evolução recente do comércio bilateral tem, no entanto, mostrado uma tendência de crescimento. A partir do início dos anos 1990, as importações brasileiras provenientes da UE, até então sistematicamente inferiores às suas exportações, apresentaram um aumento vigoroso. As importações brasileiras passaram de US\$ 5 bilhões, em 1991-1992, para cerca de US\$ 13 bilhões em 2003, tendo atingido os valores mais elevados em 1998 (mais de US\$ 17 bilhões). Por outro lado, as exportações brasileiras apresentaram uma trajetória de crescimento mais uniforme no período 1985-2003, atingindo US\$ 18 bilhões em 2003, sendo o saldo comercial novamente superavitário a partir de 2000. (p. 6).

Em termos de composição, Kume et al. (2004) enfatiza que o comércio entre o Brasil e a UE mostra um perfil típico de comércio Norte-Sul: o Brasil exporta basicamente produtos primários e seus derivados enquanto importa predominantemente bens manufaturados. De acordo com dados do MDIC (2015) em 2014 os produtos que compuseram o topo da pauta de exportação do Brasil para a UE foram: Bagaços e Outros Resíduos Sólidos da Extração do Óleo De Soja (9,52\% do total dos principais produtos exportados), Café em Grão (8\%), Soja, mesmo triturada (7,43\%), Minérios de Ferro (6,43\%) e Pasta Química de Madeira (4,89\%).

Em 2014 o Brasil importou US\$ 46,7 bilhões da UE. Dos principais produtos importados 2,97\% foram Gasolinas, 2,26\% Automóveis, 1,45\% Fungicidas, 1,13\% partes para Aviões e Helicópteros e 1,11\% Gás Natural. (MDIC, 2015). A Figura 3 apresenta a Evolução do Intercâmbio Comercial entre Brasil e EU no período abrangido pelo estudo.

Figura 3. Evolução do Intercâmbio Comercial entre Brasil e EU de 2000 a 2014 - Milhões US\$ FOB

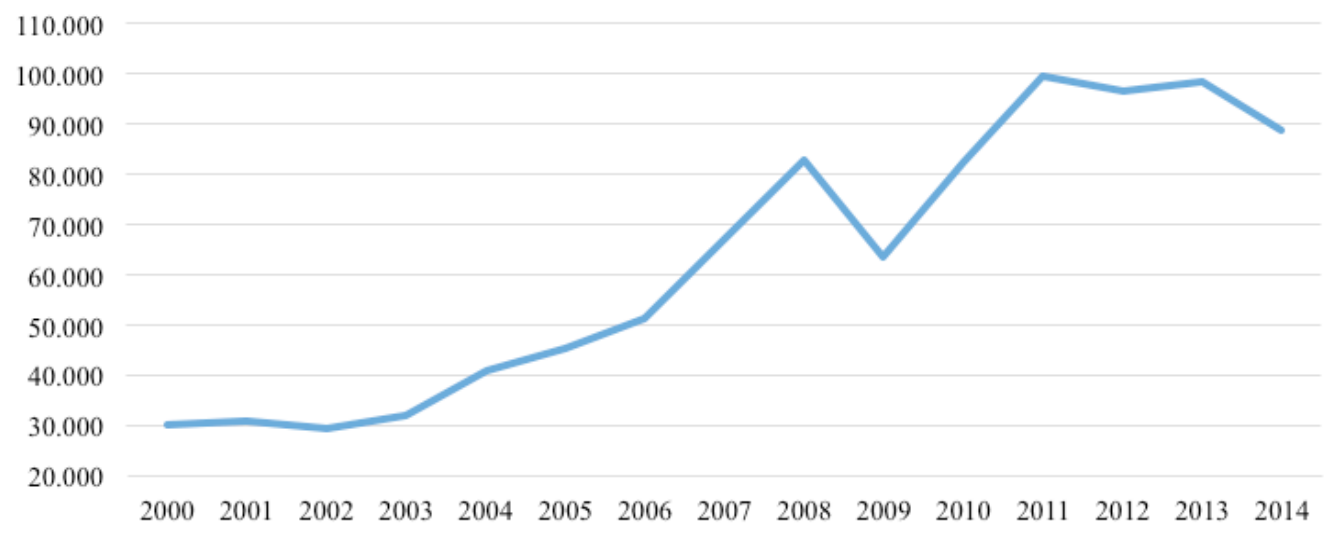

Fonte: Elaboração dos autores através de dados do MDIC (2015).

De forma geral o Efeito China deslocou um importante contingente de exportações e importações brasileiras, atraindo-as para seu mercado. A Figura 4, demonstra que a participação do comércio com a UE no comércio total do Brasil vem caindo gradativamente desde 2000, onde representava 27\%. Já em 2006 atingiu apenas 22,4\%, 22,3\% em 2008, 20,7\% em 2011, 19,5\% em 2014. 
Em relação aos acordos comerciais Brasil-UE Alvim e Waquil (2005) apresentam que dentre os acordos negociados pelo Brasil, juntamente com os demais membros do Mercosul, está o acordo com a União Europeia (UE), que tem sido apontado por diversos pesquisadores brasileiros como um potencial de ganhos para os setores agrícolas dos países do Cone Sul. Dentre as dificuldades encontradas para sua implementação está a proteção auferida pelos agricultores europeus, imposta pela Política Agrícola Comum (PAC) pelas distorções geradas nos mercados de produtos agrícolas. Ainda, em 1996 foi assinado o "Acordo-Quadro Inter-regional de Cooperação" deu início às negociações para a formação da "Associação Inter-regional" entre o Mercosul e a EU, visando aproximação e cooperação em todas as áreas.

Figura 4 - Evolução Percentual (\%) da Participação do Comércio com a EU no Comércio Total do Brasil (soma de importações e exportações).

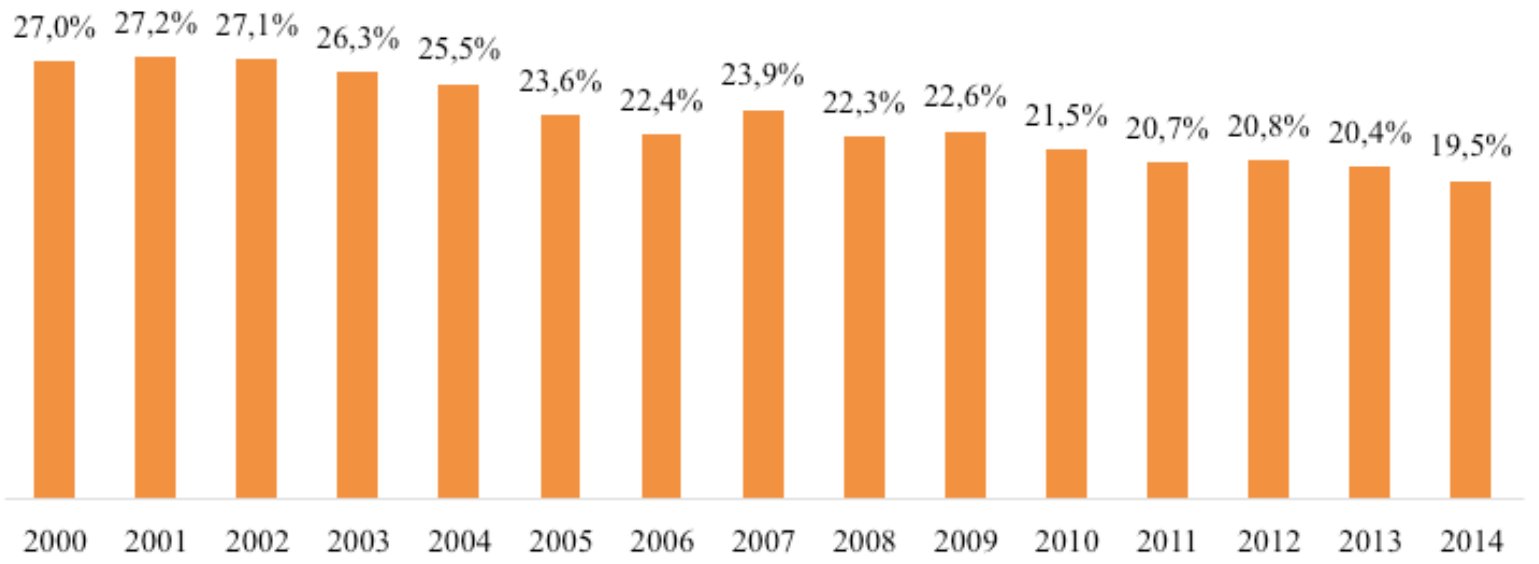

Fonte: Elaboração dos autores através de dados do MDIC (2015).

Por sua vez, Negri e Arbache (2003) demarcam que uma das características da pauta exportadora brasileira para o mercado europeu é a sua diversificação. No caso das exportações de bens agrícolas, os semimanufaturados de base agropecuária que são intensivos em trabalho, como carne, rações e fumo, corresponderam a, aproximadamente, $16 \%$ da pauta. Os primários, como soja e café, foram responsáveis por outros $16 \%$. Assim, elencados os principais aspectos do cenário de comercialização Brasil-UE são apresentados a seguir alguns estudos empíricos relacionados.

\section{Competitividade, Criação e Desvios de Comércio}

Diversos enfoques e abordagens estão sendo utilizados para averiguar tanto as relações de competitividade das exportações brasileiras em outros mercados, como os efeitos de criação e desvios de comércio provocados pela formação de acordos preferência e blocos. A exemplo disto, Negri e Arbache (2003) buscaram identificar as linhas tarifárias restringidas por tarifas específicas no mercado europeu e verificar o impacto da sua eliminação em termos do aumento das exportações do Brasil para esse mercado. Em seu estudo Negri e Arbache (2003) identificaram que as tarifas específicas têm efeitos restritivos sobre o comércio mais 
relevantes do que as tarifas, em um cenário de livre comércio, em que as tarifas específicas e as tarifas fossem zeradas, as estimativas indicaram um aumento das exportações brasileiras para o mercado europeu no montante de US\$ 691 milhões, o que equivale a um aumento de 4,62\% nas exportações se considerada a média do valor exportado entre 1998 e 2000, o que por sua vez representou uma criação de comércio.

Silva (2005) em seu estudo averiguou a competitividade dos principais produtos do complexo soja brasileiro e suas relações comerciais com o exterior através do IVCR. Os resultados evidenciaram uma perda de competitividade do mercado mundial de farelo e óleo de soja, mantendo-se, no entanto em boa situação o mercado de soja in natura. Do mesmo modo Lopes et al. (2013) buscou analisar o comportamento do mercado exportador brasileiro do complexo soja (grão e óleo) e fumo para a China, de 2000 a 2012, através do Coeficiente de Dependência das Importações (CDI) e do IOR, apontando uma orientação em relação a China, exceto para o fumo no ano de 2009. Freitas e Massuqueti (2013) avaliaram a competitividade das exportações do complexo soja do Brasil, da Argentina e dos EUA através dos índices CR e IVCR nos anos de 1995 e 2010. Em seu trabalho, os autores observaram-se vantagens comparativas para todos os produtos/países, no período, com exceção à farinha de soja para o Brasil e a Argentina.

O quadro 1 sintetiza algumas outras abordagens consideradas relevantes e as metodologias empregadas para averiguar desvios e criação de comércio em relações comerciais com a UE. Os diversos trabalhos empíricos analisados se subdividem quanto a estrutura metodológica. Estudos com a abordagem do Modelo de Equilíbrio Geral, a exemplo de Figueiredo, Ferreira e Teixeira (2001) e Oliveira e Ferreira Filho (2008), onde o primeiro avalia os efeitos que um possível acordo de livre comércio entre a União Europeia (UE) e os países da América Latina e Caribe teria sobre a agricultura brasileira e europeia enquanto o segundo apresenta os impactos setoriais mais importantes sentidos pela própria UE e pelo agronegócio brasileiro dado a expansão da UE em 2004. Outros como Nassar (2004) empregam a abordagem de equilíbrio parcial e destacam os efeitos das Barreiras Tarifárias Impostas por EUA e UE aos produtos da agroindústria Brasileira.

Quadro 1. Síntese das Abordagens e Metodologias Utilizadas para averiguar Desvios e Criação de Comércio em relações comerciais com a UE

\begin{tabular}{|c|c|c|c|}
\hline Autores & Objetivo & Método & Resultados \\
\hline $\begin{array}{c}\text { Alvim e Waquil } \\
\qquad(2005)\end{array}$ & $\begin{array}{c}\text { Mensurar os efeitos do acordo } \\
\text { entre o Mercosul e a União Eu- } \\
\text { ropeia (UE) sobre a produção, } \\
\text { consumo e fluxos comerciais } \\
\text { de arroz, milho, soja e trigo } \\
\text { nas diversas regiões. }\end{array}$ & $\begin{array}{c}\text { Modelo de alocação espacial } \\
\text { apresentado como um Proble- } \\
\text { ma de Complementaridade } \\
\text { Mista (PCM) }\end{array}$ & $\begin{array}{l}\text { Ganhos para os produtores } \\
\text { de grãos dos países do Mer- } \\
\text { cosul ocorrem no cenário } \\
\text { Mercosul-UE com eliminação } \\
\text { dos subsídios por parte dos } \\
\text { países da UE. No entanto, } \\
\text { salienta-se que, embora os } \\
\text { ganhos totais para os países } \\
\text { do Mercosul sejam positivos, } \\
\text { o setor tritícola apresenta } \\
\text { perdas significativas neste } \\
\text { cenário. }\end{array}$ \\
\hline
\end{tabular}


(continuação)

\begin{tabular}{|c|c|c|c|}
\hline $\begin{array}{l}\text { Figueiredo, } \\
\text { Ferreira e Teixeira } \\
\text { (2001) }\end{array}$ & $\begin{array}{c}\text { Avaliar os efeitos que um } \\
\text { possível acordo de livre } \\
\text { comércio entre a União } \\
\text { Europeia (UE) e os países da } \\
\text { América Latina e Caribe teria } \\
\text { sobre a agricultura brasileira } \\
\text { e europeia. }\end{array}$ & $\begin{array}{l}\text { Modelo de equilíbrio Geral } \\
\text { (GTAP) }\end{array}$ & $\begin{array}{l}\text { Os resultados indicam, } \\
\text { para o Brasil, crescimento } \\
\text { econômico de } 3,9 \% \text { a } \\
\text { 6,3\% para os diferentes } \\
\text { cenários, e, para a UE, } \\
\text { de } 0,3 \% \text { a } 1,8 \% \text {. Os } \\
\text { benefícios da liberalização } \\
\text { seriam concentrados } \\
\text { nos setores de maior } \\
\text { vantagem comparativa, } \\
\text { agronegócio para o Brasil e } \\
\text { manufaturados para a EU, } \\
\text { com a criação de comércio. }\end{array}$ \\
\hline $\begin{array}{l}\text { Piani e Kume } \\
\quad(2000)\end{array}$ & $\begin{array}{c}\text { Avaliar a evolução dos } \\
\text { fluxos bilaterais de comércio } \\
\text { internacional entre } 44 \text { países } \\
\text { e, em particular, os efeitos } \\
\text { de acordos preferenciais de } \\
\text { seis blocos econômicos, no } \\
\text { período } 1986 / 97 \text {. }\end{array}$ & Modelo Gravitacional & $\begin{array}{c}\text { A análise confirma a } \\
\text { importância dos vários tipos } \\
\text { de acordos regionais de } \\
\text { livre comércio para a criação } \\
\text { de um nível extraordinário } \\
\text { de trocas comerciais } \\
\text { entre os países membros, } \\
\text { em todos os seis blocos, } \\
\text { independentemente de } \\
\text { serem compostos por países } \\
\text { desenvolvidos ou não }\end{array}$ \\
\hline $\begin{array}{l}\text { Oliveira e Ferreira } \\
\text { Filho (2008) }\end{array}$ & $\begin{array}{l}\text { Determinar o impacto da } \\
\text { expansão da EU em } 2004 \text { no } \\
\text { agronegócio brasileiro. }\end{array}$ & $\begin{array}{l}\text { Modelo de Equilíbrio Geral } \\
\text { (GTAP) }\end{array}$ & $\begin{array}{l}\text { Os impactos setoriais } \\
\text { mais importantes foram } \\
\text { sentidos na própria UE, } \\
\text { como esperado, já que as } \\
\text { medidas ocorrem naquele } \\
\text { bloco. O impacto agregado } \\
\text { da expansão da UE não foi } \\
\text { importante para a economia } \\
\text { brasileira. As exportações } \\
\text { de setores da economia } \\
\text { como agronegócio, } \\
\text { oleaginosas e carne bovina } \\
\text { cresceram com a expansão } \\
\text { e o descasamento dos } \\
\text { pagamentos diretos, } \\
\text { embora tenham decrescido } \\
\text { com a expansão da UE sem } \\
\text { o descasamento. }\end{array}$ \\
\hline Nassar (2004) & $\begin{array}{l}\text { Análise das Barreiras } \\
\text { Tarifárias Impostas por } \\
\text { EUA e EU aos produtos da } \\
\text { agroindústria Brasileira. }\end{array}$ & Modelo de Equilíbrio Parcial & $\begin{array}{c}\text { Os resultados agregados } \\
\text { mostram que as } \\
\text { exportações dos EUA } \\
\text { cresceriam } 94 \% \text { e as } \\
\text { europeias } 95 \% \text {, para } \\
\text { o cenário de } 100 \% \text { de } \\
\text { redução tarifária. Neste } \\
\text { cenário ambos os mercados } \\
\text { demandariam volumes } \\
\text { maiores de produtos que } \\
\text { são exportados pelo Brasil. }\end{array}$ \\
\hline
\end{tabular}


(continuação)

\begin{tabular}{|c|c|c|c|}
\hline Luz (1997) & $\begin{array}{c}\text { Quantificação da resposta } \\
\text { das exportações portugue- } \\
\text { sas para os países europeus } \\
\text { à presença de barreiras ao } \\
\text { comércio. }\end{array}$ & Modelo Gravitacional & $\begin{array}{c}\text { Importância decisiva para o } \\
\text { comércio externo português } \\
\text { do levantamento das barrei- } \\
\text { ras alfandegárias, prevendo- } \\
\text {-se uma grande relevância } \\
\text { dos elementos de criação } \\
\text { de comércio no que respeita } \\
\text { às perspectivas de evolução } \\
\text { futura das trocas comerciais } \\
\text { entre Portugal e os países } \\
\text { do centro e leste europeu. }\end{array}$ \\
\hline
\end{tabular}

Fonte: Elaboração dos Autores.

Alvim e Waquil (2005), por sua vez, diferem dos demais por utilizar um modelo de alocação espacial apresentado como um Problema de Complementaridade Mista (PCM) para mensurar os efeitos do acordo entre o Mercosul e a União Europeia (UE) sobre a produção, consumo e fluxos comerciais de arroz, milho, soja e trigo nas diversas regiões. O estudo proposto evidenciou ganhos para os produtores de grãos dos países do Mercosul no cenário Mercosul-UE com eliminação dos subsídios por parte dos países da UE. Ressalta-se ainda os trabalhos de Piani e Kume (2000) e Luz (1997) que inserem a abordagem do modelo gravitacional como forma de obtenção de resultados para fluxos bilaterais de comércio internacional. Depois de demarcados alguns estudos empíricos são apresentados na próxima seção os procedimentos metodológicos utilizados na investigação.

\section{Material e Método}

O presente estudo tem por objetivo verificar a competitividade e orientação das exportações brasileira de milho frente à União Europeia, buscando indício de criação e desvio de comércio. O mesmo será concebido através da pesquisa científica de cunho descritivo, com abordagem quantitativa e através do método dedutivo. A coleta de dados realizou-se através de pesquisa bibliográfica nas bases do USDA e UN Comtrade.

A pesquisa descritiva, segundo Gil (2010), possui como objetivo descrever as características de uma determinada população ou fenômeno ou o estabelecimento de relações entre as variáveis. Por seu turno a abordagem quantitativa representa a utilização de termos numéricos, Hair Jr. et al. (2005) caracterizam a abordagem quantitativa como sendo mensurações numéricas que representam as propriedades de algo, utilizando-se da análise estatística.

Cabe ressaltar, com base em Pradanov e Freitas (2013), que o raciocínio dedutivo: "[...] tem o objetivo de explicar o conteúdo das premissas. Por intermédio de uma cadeia de raciocínio em ordem descendente, de análise do geral para o particular, chega a uma conclusão" (p. 27). Quanto a coleta de dados através de pesquisa bibliográfica ela ocorre a partir de material já publicado. Assim, os instrumentos utilizados para esta pesquisa serão a análise de documentos de fontes secundárias nos temas: milho, comércio Brasil UE, competitividade, orientação regional e desvios e criação de comércio. 
Definiu-se como recorte o espaço geográfico de relações comerciais entre o Brasil e a União Europeia. A metodologia usada para avaliar se ocorreu criação ou desvio de comércio calcula o Índice de Orientação Regional (IOR) no período de 2000 a 2014, a fim de evidenciar onde ocorre um maior crescimento no comércio entre Brasil e UE para o período. Além disso, será calculado o Índice de Vantagens Comparativas Reveladas (IVCR) para verificar se a evolução do comércio é compatível com as vantagens comparativas reveladas dos países.

O Índice de Orientação Regional (IOR) será usado com o objetivo de observar a direção das exportações. $O$ índice é calculado através da razão entre o percentual das exportações do produto "k" sobre o total de exportações do país "i" para dentro do bloco pelas exportações do produto "k" do país "i" para todo o mundo sobre o total exportado pelo país extrabloco. Sendo assim, o índice pode ser assim expresso:

$$
\frac{X_{i k}}{X_{i t}} / \frac{X_{e k}}{X_{e t}}
$$

Onde:

$\mathrm{X}_{\mathrm{ik}}$ : valor das exportações intra-bloco do produto k;

$\mathrm{X}_{\mathrm{it}}$ : valor total das exportações intra-bloco;

$\mathrm{X}_{\mathrm{ek}}$ : valor das exportações extra-bloco do produto k;

$\mathrm{X}_{\mathrm{et}}$ : valor total das exportações extra-bloco.

Se o resultado encontrado para o índice for maior que a unidade, isto demonstra uma tendência do país "i" a exportar mais para países membro do bloco, aumentando a sua integração comercial. Já se for igual à unidade, pode se dizer que indica a mesma tendência tanto para exportar para dentro quanto fora do bloco. Por fim, se for menor que a unidade, pode-se dizer que as exportações do país "i" estão voltadas para fora do bloco.

O Índice de Vantagem Comparativa Revelada (IVCR), criado por Balassa (1965), busca medir os produtos nos quais um determinado país "i" produz com maior eficiência em relação ao restante dos países do mundo, baseando-se para isso nos fluxos de comércio passado de um determinado produto "k" em relação à exportação total do país "i", ou seja, no percentual que o produto "k" tem sobre a pauta de exportação do país "i", comparada com a exportação total mundial do produto "k" em relação à exportação total mundial. O índice poder ser especificado pela fórmula:

$$
I V C R_{b k}=\frac{X_{b k}}{X_{b t}} / \frac{X_{w k}}{X_{w t}}
$$

Onde:

$\mathrm{X}_{\mathrm{bk}}$ : valor das exportações do país/bloco b do produto k;

$\mathrm{X}_{\mathrm{bt}}$ : valor total das exportações do país/bloco b;

$\mathrm{X}_{\mathrm{wk}}$ : valor das exportações mundiais do produto k;

$\mathrm{X}_{\mathrm{wt}}:$ valor total das exportações mundiais. 
Quando o resultado do IVCR for maior que um, pode-se afirmar que o país tem vantagem comparativa revelada do produto em relação ao resto do mundo. Quanto mais alto for o IVCR, maior será a vantagem do país comparada aos demais países na produção deste produto. Quando o índice for igual a um, o país está em iguais condições na produção do produto em relação ao resto do mundo. Já quando o IVCR for menor que um significa que o resto do mundo possui vantagem comparativa revelada na produção do produto em relação ao país.

Porém, alguns pontos são interessantes de serem ressaltados sobre esses índices. O IOR, segundo Yeats (1997) passa uma informação limitada sobre o padrão de comércio se analisado de forma isolada no tempo, já em uma comparação intertemporal em períodos relativamente curtos pode fornecer informações interessantes sobre como o padrão de comércio está mudando, considerando que a orientação geográfica do comércio é determinada pelos custos de transportes, barreiras comerciais em mercados alternativos, vantagem comparativa revelada entre outros e esses geralmente são estáveis no curto e médio prazo. Diversos trabalhos usaram o índice para mensurar a tendência das exportações de alguns produtos do agronegócio brasileiro, merecem destaque os de Yeats (1997), Waquil et al. (2004), Rubin e Rondinel (2004), Ilha e Souza (2005) e Ilha e Coronel (2003).

Sobre o IVCR, Yeats (1997) pontua que ele é mais usado para produtos manufaturados, pois quando calculado para produtos agrícolas, o índice pode ter uma distorção no seu resultado por ser este um setor fortemente influenciado pelos incentivos dos governos. Freitas e Massuqueti (2013) apresenta que o índice pressupõe que a medida de competitividade de determinado país seja explicada por meio do seu desempenho no comércio internacional, os equívocos aí residem para aqueles casos de produtos que possuem desoneração em alguma alíquota para exportação, subsídios, restrições quantitativas, tarifas de importação entre outros. Kupfer (1993), no entanto, relaciona a competitividade ao desempenho das exportações, enquanto Figueiredo e Santos (2005) comentam que as limitações ao seu uso surgem devido a noção de vantagem comparativa revelada estar interligada a fatores estruturais do processo produtivo, ou seja, aos custos de produção. $O$ índice tem uma ampla utilização em estudos de produtos agroalimentares por permitir comparações desejadas, principalmente em relação a evolução da competitividade do setor/produto analisado (trabalhos como Maia (2002), Ferreira e Carvalho (1998), David e Nonnenberg (1998), Waquil et al. (2004)), justifica-se, dessa forma, de sua utilização.

\section{Resultados e Discussão}

A maior competitividade da agricultura brasileira vem garantindo crescimento nas exportações de milho. As vendas do grão aumentaram 13,6\% até outubro de 2015, assegurando ao País uma receita de mais de US\$ 3 bilhões no ano. Em igual período de 2014, o milho tinha obtido US\$ 2,7 bilhões em vendas externas. Em quantidade, as remessas de milho acumuladas entre janeiro e outubro de 2015 somaram 17,9 milhões de toneladas. Nos dez primeiros meses de 2014, haviam sido enviadas ao exterior 14,2 milhões de toneladas do grão colhido no Brasil. O que representou uma elevação de $25,4 \%$ nas as quantidades exportadas e, consequentemente, no valor obtido com as vendas ao mercado internacional (MDIC, 2015). 
A participação das exportações de milho do Brasil para UE do total exportado do grão pelo país, cresceu em média 27,5\% nos 14 anos analisados pelo estudo. Entre 2007 e 2008 que foram anos de pico de comercialização do grão $89,77 \%$ e $83,04 \%$, respectivamente, das exportações de milho tinham como destino o bloco, ainda, de 2006 para 2007 as exportações do grão para UE elevaram-se no patamar de $298 \%$, significando uma receita expressiva para o Brasil.

Com o objetivo de verificar a competitividade das exportações brasileira de milho frente à União Europeia e sua orientação em relação ao bloco, realizou-se o cálculo do IVCR e do IOR.

\section{Índice de Orientação Regional}

Com relação a Orientação Regional das exportações de milho, predominantemente o IOR estabeleceu-se abaixo de 1, indicando que as exportações do país não estão direcionadas para o bloco. Quando observados anos específicos verifica-se que indicador se estabeleceu acima de 1, a exemplo de 2003 (1,69), 2004 (1,90), $2006(1,15), 2007(3,19)$ e $2008(3,14)$, o que indica que nestes anos especificamente as exportações brasileiras de milho estavam orientadas para a UE, período que condiz a pela rápida industrialização de países emergentes, especialmente China e Índia que amparou por mais de uma década o crescimento do Brasil puxado pelo mercado de grãos no cenário internacional. A Figura 5 apresenta a evolução do IOR de 2000 a 2014.

Em estudo anterior Silva et al. (2010) verificou significativa oscilação no índice para o período de 1997 a 2008, a justificativa utilizada para os períodos em que as exportações não se caracterizaram orientadas para o bloco foi a de que a maior parte do milho produzido no Brasil (aproximadamente $80 \%$ ) é destinada para suprir a demanda interna. No estudo dos autores os anos de 2007 e 2008 também apresentaram significativa elevação em comparação com os demais anos, o que segundo estes significava uma tendência de direcionamento para a União Europeia, tendência esta, que como visualizada na Figura 5, inverteu-se a partir de 2009.

Figura 5. Evolução do IOR de 2000 a 2014

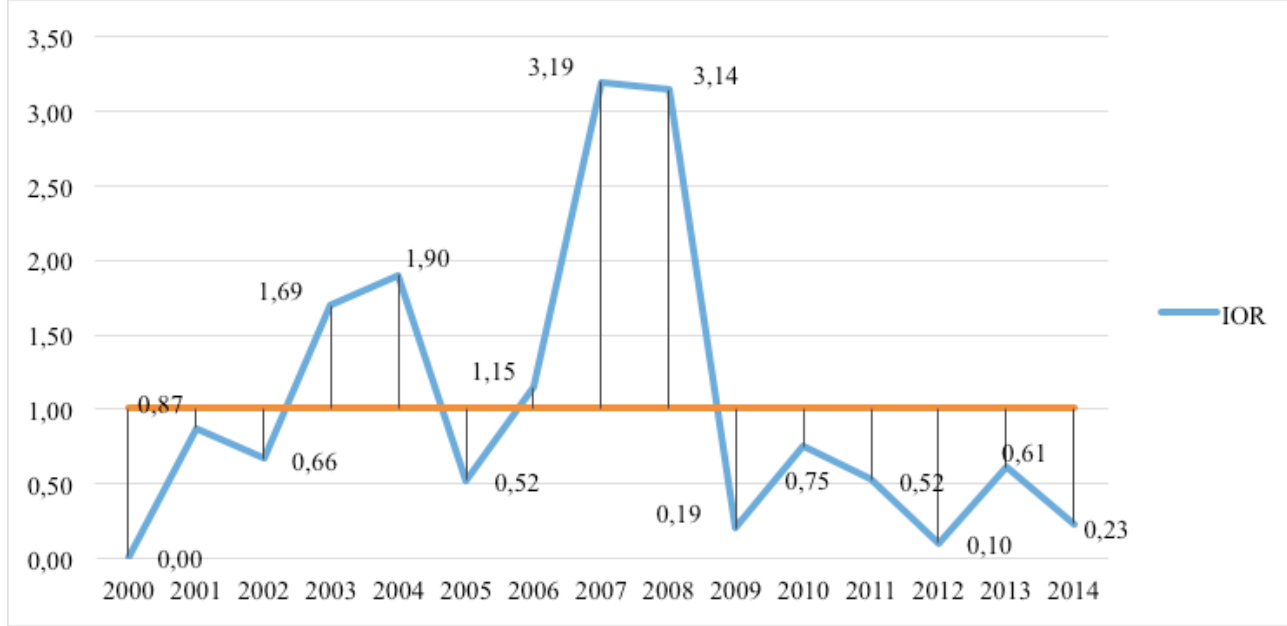

Fonte: Elaboração dos Autores. 
O pico de comercialização com a UE nos anos de 2007 e 2008 pode ser explicado pelo ciclo de alta nos preços que ocorreu nos respectivos anos. Segundo informações da Embrapa Milho e Sorgo (2012) o preço do grão atingiu patamares recordes no final de 2007 e início de 2008, devido à alta demanda norte-americana por milho para a produção de etanol e, posteriormente, a um problema de oferta de trigo no mercado internacional que fez com que o milho fosse utilizado como substituto da cultura. O Brasil no final de 2007 atingiu um volume recorde de exportações, superando 10 milhões de toneladas.

\section{Î́ndice de Vantagem Comparativa Revelada}

Quando ao Índice de Vantagem Comparativa Revelada verifica-se que o mesmo se estabeleceu abaixo da unidade para todo o período analisado, indicado que o país não possui vantagem comparativa na produção do grão em relação ao resto do mundo, ou seja, o resto do mundo possui vantagem comparativa revelada na produção do produto em relação ao país. Porém, o índice caracterizou-se como crescente assinalando uma tendência de aumento de competitividade do grão. A Figura 6 evidencia a evolução do IVCR de 2000 a 2014. Os anos de 2003, 2004, 2006, 2007 e 2008 são típicos para representar um possível desvio de comércio, sendo que a orientação em relação à exportação para UE era significativa, ou seja, como já foi apresentado anteriormente o Brasil exportou mais para o bloco nesses anos, um produto que, conforme indicado pelo IVCR não representa vantagem revelada na pauta exportadora do país. Sendo assim, a UE acaba recebendo um produto menos eficiente.

Figura 6. Evolução do IVCR de 2000 a 2014

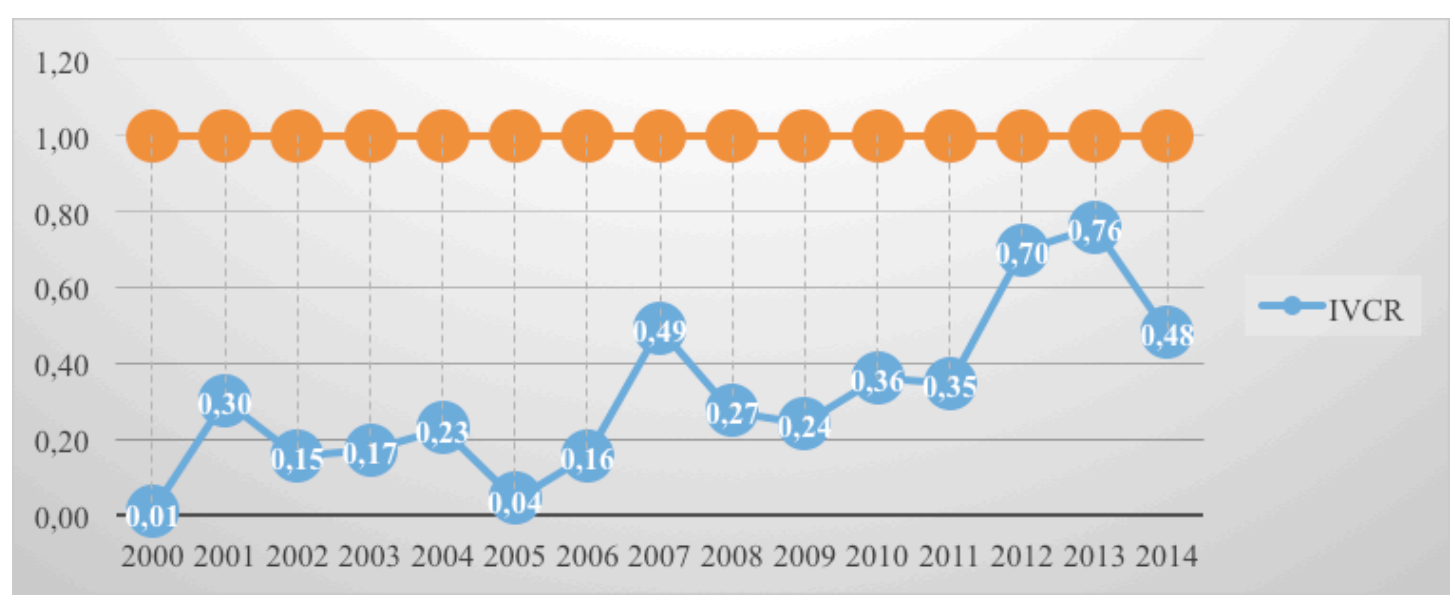

Fonte: Elaboração dos Autores.

Estudos anteriores como os de Alvim e Waquil (2005) demonstraram, no entanto, que mesmo em um cenário de liberalização do comércio entre Brasil-UE não existe um ganho significativo para o mercado do milho em função da posição estratégica dos EUA junto ao mercado europeu. Isto, devido aos subsídios que os agricultores americanos recebem para a produção 
que ampliam a sua capacidade de exportação para terceiros mercados. Silva et al. (2010) demarca que, quando considerado o setor de grãos como um todo, o Brasil possui Vantagem Comparativa Revelada, sendo este mercado impulsionado principalmente pela soja, na qual se concentram as principais exportações de grãos do país.

\section{Considerações Finais}

A redução do protecionismo e a consequente liberalização do comércio agrícola têm aparecido como um dos principais pontos frente a expansão do comércio internacional destes produtos. A ampliação e integração dos mercados agrícolas pode ser capaz de impulsionar os fluxos comerciais entre os países envolvidos, permitindo crescimento e desenvolvimento destas economias, como também, garantindo um melhor acesso a uma maior variedade de produtos, o que se torna peça chave no âmbito da insegurança alimentar que acomete muitas nações.

O estudo objetivou verificar a competitividade e a orientação das exportações brasileira de milho frente à União Europeia. Identificou-se que o milho não apresentou vantagem comparativa revelada na pauta exportadora brasileira de 2000 a 2014. Do mesmo modo, apesar da expansão das exportações do grão para a UE, verificou-se que não existe uma orientação neste sentido, com exceção de alguns anos específicos que, condicionados pela oscilação das exportações e preço do grão, expandiram as possibilidades deste mercado.

Os preços do milho estão em grande parte determinado por relações de oferta e demanda no mercado de EUA, maior exportador mundial do grão. Os preços internacionais atraentes no decorrer dos tempos fizeram com que inúmeros países expandissem sua oferta, a exemplo do Brasil. Os países em desenvolvimento têm continuado a aumentar as importações de milho desde 1980, caracterizando a importância do grão mercado internacional. Nesse sentido, a demanda externa não depende apenas de países importadores, mas de mudanças políticas internas e práticas para tornar a concorrência mais leal. O livre comércio é a principal arma para isto.

\section{Referências}

Alvim, A. M. \&Waquil, P. D. (2005). Efeitos do Acordo entre Brasil e União Europeia sobre o mercado de grãos. Revista de Economia e Sociologia Rural, Brasília, 43 (4), out./dez, p. 703-723. Disponível em: <http://www.scielo.br/pdf/resr/v43n4/27752.pdf>. Acesso em 19 out. 2015.

Balassa, B. (1965). Trade Liberalization and "Revealed" Comparative Advantage. The Manchester School of Economic and Social Studies, 32, p. 99-123.

Baumann, R., Canuto, O. \& Gonçalves, R. (2004). Teorias do investimento internacional. In: J. A. De Negri \& M. S. Salerno, Economia Internacional: Teoria Experiência Brasileira (p. 199-220). Rio De Janeiro: Elsevier.

Brandão, F. S. et-al (2012). O papel do agronegócio brasileiro na redução de emissão de gases de efeito estufa (GEES). Revista Agro@mbiente On-line, 6 (1), 84-90, jan./ abr. Disponível em: < http:// revista.ufrr.br/index.php/agroambiente/article/viewFile/642/663>. Acesso em 20 jun. 2016. 
Caldarelli, C. E. \& Bacchi, M. R. P. (2012). Fatores de influência no preço do milho no Brasil. Revista Nova Economia, 22, 141-164.

David, M. B. de A. \& Nonnenberg, M. J. B. (1998). Ganhos e perdas de competitividade: os efeitos do Mercosul. In: XXXVI Congresso Da Sociedade Brasileira de Economia E Sociologia Rural. Poços de Caldas: SOBER, Anais. p. 1-18.

Empresa Brasileira de Pesquisa Agropecuária (Embrapa). 2012. Disponível em: < http://www. cnpms.embrapa.br/milho/cultivares/\#>. Acesso em: 25 fev. 2015.

Favro, J., Caldarelli, C. E. \& Camara, M. R. G. da. (2015). Modelo de Análise da Oferta de Exportação de Milho Brasileira: 2001 a 2012. Rev. Econ. Sociol. Rural, 53 (3), 455-476, jul./ set. Disponível em: <http://www.scielo.br/scielo.php?script=sci_arttext\&pid=S0103-20032015000300455>. Acesso em 20 jun. 2016.

Ferreira, A. V. \& Carvalho, F. M. de A. C. (1998). Indicadores de competitividade das exportações agroindustriais brasileiras, 1980-1995. In: XXXVI Congresso da Sociedade Brasileira de Economia e Sociologia Rural Poços de Caldas: SOBER. Anais.

Figueiredo, A. M. R, Ferreira, A. V. \& Teixeira, Erly C. (2001). Impactos da Integração Econômica nas Commodities da Economia Brasileira e da União Européia. Revista Brasileira de Economia, 55 (1), jan. / mar., 77-106. Disponível em: <http://www.scielo.br/pdf/rbe/v55n1/a04v55n1. pdf. >. Acesso em 19 out. 2015.

Figueiredo, A. M. \& Santos, M. L. (2005). Evolução das Vantagens Comparativas do Brasil no Comércio Mundial da Soja. Revista de Política Agrícola, 5, 9-16.

Food and Agriculture Organization of the United Nations - FAO. (2015). Divisão de estatísticas - FAOSTAT. Disponível em: <http://faostat3.fao.org/home/E>. Acesso em: 19 out. 2015.

Freitas, G. da S. \& Massuquetti, A. (2013). A Competitividade e o Grau de Concentração das Exportações do Complexo Soja do Brasil, da Argentina e dos Estados Unidos da América No Período 1995/2010. REGET, 16 (16), nov., p. 3113- 3133. Disponível em: <http://periodicos. ufsm.br/reget/article/viewFile/10602/pdf>. Acesso em 20 jun. 2016.

Gabinete de Estatístisticas da União Européia - Eurostat. Disponível em:<http://ec.europa.eu/ eurostat/web/international-trade/data/database>. Acesso em: 19 out. 2015.

Gil, A. C. (2010). Como Elaborar Projetos de Pesquisa, 5. ed. São Paulo: Atlas.

Giordano, S. R. (1999). Competitividade Regional e Globalização. Tese de Doutorado. Faculdade de Filosofia, Letras e Ciências Humanas da Universidade de São Paulo.

Gorender, J. (1995). Estratégias dos Estados nacionais diante do processo de globalização. Estudos Avançados, 9 (25), 93-112. Disponível em: <http://www.scielo.br/pdf/ea/v9n25/ v9n25a07.pdf>. Acesso em 12 jan. 2016.

Guimarães, E. (2000). Componente Tecnológico Comparativo das Exportações ao Mercosul e ao Resto do Mundo. Brasília, IPEA. (Texto para discussão, №. 765). Disponível em: < http://www. ipea.gov.br/portal/images/stories/PDFs/TDs/td_0765.pdf>. Acesso em 21 jun. 2016.

Hair Jr., J. F., et-al. (2005). Fundamentos de métodos de pesquisa em administração. Porto Alegre: Bookman. 
Ilha, A. da S. \& Coronel, D. A. (2003). Vantagens Comparativas Reveladas e Orientação Regional da soja brasileira frente à União Européia e ao Foro de Cooperação Econômica na Ásia e no Pacífico (1992-2002). Revista de Economia e Agronegócio, 4 (1), 43-62, jan./mar.

Ilha, A. da S. \& Souza, M. J. P. de. (2005). Índices de vantagem comparativas reveladas e orientação regional para alguns produtos do agronegócio brasileiro no período de 1992 a 2002. In XLIII Congresso Brasileiro de Economia e Sociologia Rural, XLIII., 2005., Ribeirão Preto. Anais. Piracicaba: SOBER.

Irwin, S. H. \& Good, D. L. (2009). Market instability in a new era of corn, soybean, and wheat prices. Choices, 24 (1), 6-11.

Kume, H., Piani, G., Miranda, P. \& Castilho, M. (2004). Acordo de livre-comércio Mercosul-União Europeia: uma estimativa dos impactos no comércio brasileiro. Rio de Janeiro: IPEA, nov.

Kupfer, D. (1993). Padrões de Concorrência e Competitividade. Rio de Janeiro: IEI / UFRJ. (Texto para discussão n²65).

Lopes, M. M., et-al. (2013). Análise da Competitividade das Exportações Agrícolas Brasileiras para a China: Uma Análise de complexo soja e fumo. Revista Uniabeu, 6 (13), maio / ago., 189-208. Disponível em: <http://www.uniabeu.edu.br/publica/index.php/RU/article/ view/973/pdf_11>. Acesso em: 11 fev. 2016.

Luz, S. (1997). Alargamento da União Europeia e Comercio Externo Português. Banco de Portugual Boletim Econômico, mar. Disponível em: < http://www.bportugal.pt/pt-PT/BdP\%20 Publicaes\%20de\%20Investigao/AB199703_p.pdf>. Acesso em 19 out. 2015.

Maia, S. F.(2002). Impactos da abertura econômica sobre as exportações agrícolas brasileiras: analise comparativa. In: XL Congresso Brasileiro da Sociedade Brasileiro de Economia e Sociologia Rural. Passo Fundo: SOBER, Anais,1-20.

Ministério da Agricultura Pecuária e Abastecimento - MAPA, 2015. Disponível em: <http:// www.agricultura.gov.br/vegetal/culturas/milho>. Acesso em: 11 fev. 2016.

Ministério do Desenvolvimento Indústria e Comércio Exterior - MDIC, 2015. Disponível em: <http://www.mdic.gov.br/sitio/>. Acesso em: 11 fev. 2016.

Nassar, A. M. (2004). Produtos da agroindústria de exportação brasileira: uma análise das barreiras tarifárias impostas por Estados Unidos e União Europeia. Teses USP. Disponível: < http://www.teses.usp.br/teses/disponiveis/12/12139/tde-11012006-154745/en.php>. Acesso em 19 out. 2015.

Negri, J. A. \& Arbache, J. S. (2003). O impacto de um acordo entre o Mercosul e a União Europeia sobre o potencial exportador brasileiro para o mercado europeu. Brasília: IPEA. (Texto para Discussão n 990).

Nonnenberg, M. J. B. \& Mendonça, M. J. C. (1999). Criação e desvio de comércio no Mercosul: o caso dos produtos agrícolas. Rio de Janeiro: IPEA. (Texto para Discussão, 631). Disponível em: <http://www.ipea.gov.br/portal/index.php?option=com_content\&view=article\&id=3941>. Acesso em 21 jun. 2016. 
Oliveira, S. J. de M. \& Ferreira Filho, J. B. de S. (2008). A expansão da União Europeia em 2004 e seus impactos no agronegócio brasileiro. Revista de Economia e Sociologia Rural, Brasília, v. 46, n. 4, out./ dez., 937-967. Disponível em: < http://www.scielo.br/pdf/resr/v46n4/ v46n4a02.pdf>. Acesso em 19 out. 2015.

Piani, Guida \& Kume, H. (2000). Fluxos Bilaterais de Comércio e Blocos Regionais: Uma aplicação do Modelo Gravitacional. Texto para Discussão IPEA, n. 749, jul., 1-17. Disponível em: <http://repositorio.ipea.gov.br/bitstream/11058/2279/1/TD_749.pdf>. Acesso em: 09 mar. 2014.

Portal Oficial da União Européia. Disponível em: <http://europa.eu/index_pt.htm>. Acesso em: 19 out. 2015.

Pradanov, C. C. \& Freitas, E. C. de. (2013). Metodologia do Trabalho Científico: Métodos e Técnicas da Pesquisa e do Trabalho Acadêmico [Recurso Digital]. 2. ed. Novo Hamburgo: Feevale.

Reis, M. Do \& Azevedo, A. F. Z. (2008). O impacto da criação do Mercosul no fluxo de comercio bilateral: Uma abordagem com o modelo gravitacional. In: XXXVI Encontro Nacional de Economia, Niterói. Disponível em: <http://www.anpec.org.br/encontro2008/artigos/200807211656390-.pdf>. Acesso em 19 out. 2015.

Rubin, L. da S. \& Rondinel, R. (2004).Vantagens comparativas e orientação das exportações: estudo de caso do café, do fumo e da soja no período 1989-2001. Revista de Integração Latino Americana (RILA), Santa Maria, 1 (1),143-162.

Silva, F.A., et-al. (2010). Padrão da Inserção Brasileira no Mercado Internacional de Grãos. In: $48^{\circ}$ Congresso da Sociedade Brasileira de Economia, Administração e Sociologia Rural, Campo Grande.

Silva, O. C. da. (2005). Análise da competitividade do complexo Soja Brasileiro perante o Comércio Internacional. UFPR - (Dissertação) Universidade Federal do Paraná, Curitiba. Disponível em: <http://www.economia.ufpr.br/Teses\%20Doutorado/Oscar\%20Custel\%20da\%20 Silva.pdp>. Acesso em: 11 fev. 2016.

Slater, S. F. (2001). Market orientation at the beginning of a new millennium. Managing Service Quality, 11, 230-232.

The United Nations Commodity Trade Statistics Database (Un Comtrade). Disponível em: <http://comtrade.un.org/>. Acesso em: 26 set. 2015.

United States Department of Agriculture (USDA). Disponível em: <http://www.usda.gov/wps/ portal/usda/usdahome>. Acesso em 09 fev. 2016.

Viner, J. (1950). The Customs Union Issue. NY: Carnegie Endowment for International Peace.

Yeats, A. (1997). Does mercosur's trade performance raise concerns about the effects of regional trade arrangements? Policy, Planning and Research Working Paper No 1729, Washington D.C, World Bank.

Waquil, P. D., et-al. (2004). Vantagens comparativas reveladas e orientação regional das exportações agrícolas brasileiras para a União Europeia. Revista de Economia e Agronegócio, Viçosa, 2 (2), 137-160. 